\title{
AHP Based Evaluation Model of Energy Efficiency for Energy Internet
}

\author{
Qing Wang ${ }^{1,}$, Song $\mathrm{Liu}^{2}$, Congcong $\mathrm{Li}^{1}$, Chao $\mathrm{Yu}^{3}$ and Yanxi $\mathrm{Liu}^{3}$ \\ ${ }^{1}$ State Grid Shandong Electric Power Research Institute Jinan 250000, China \\ ${ }^{2}$ North China Electric Power University 102206, China \\ ${ }^{3}$ Marketing Service Center (Metering Center) State Grid Shandong Electric Power Company Jinan 250000, China
}

\begin{abstract}
The emerging construction of China's industry park requires for a specific evaluation method for the local energy internet's power utilization efficiency. This article focuses on the solar power exploitation from power supply reliability, energy utilization efficiency, solar power general efficiency, established a complete energy internet evaluation index system using improved analytic hierarchy process (AHP). Such method was proved to be more delicate to evaluate the solar-involved park energy internet comparing to traditional methods. The energy internet of a certain industry park was taken as an example for verification. It was found that the improved AHP method can objectively reflect the planning's efficiency from multiindicators. When evaluating from different perspective, focusing on a different characteristic of the regional power grid will lead to changes in the AHP evaluation weighting and the results. According to the evaluation result, the relevant suggestions to improve energy efficiency were also proposed.
\end{abstract}

\section{INTRODUCTION}

The Energy Internet has flourished in recent years, which is a combination of traditional energy grid, new energy technology and artificial intelligence technology. The Energy Internet optimizes and coordinates electricity, heat, gas and other energy networks, as well as widelyconnected distributed energy, energy storage systems, and energy loads to achieve energy and information Peer-topeer exchange and sharing. Due to the complementary characteristics of different types of energy, the Energy Internet is expected to increase terminal energy utilization efficiency through energy cascade utilization. Demandside response based on big data and wide-area information platforms improves the utilization efficiency of energy production and transmission facilities [1].

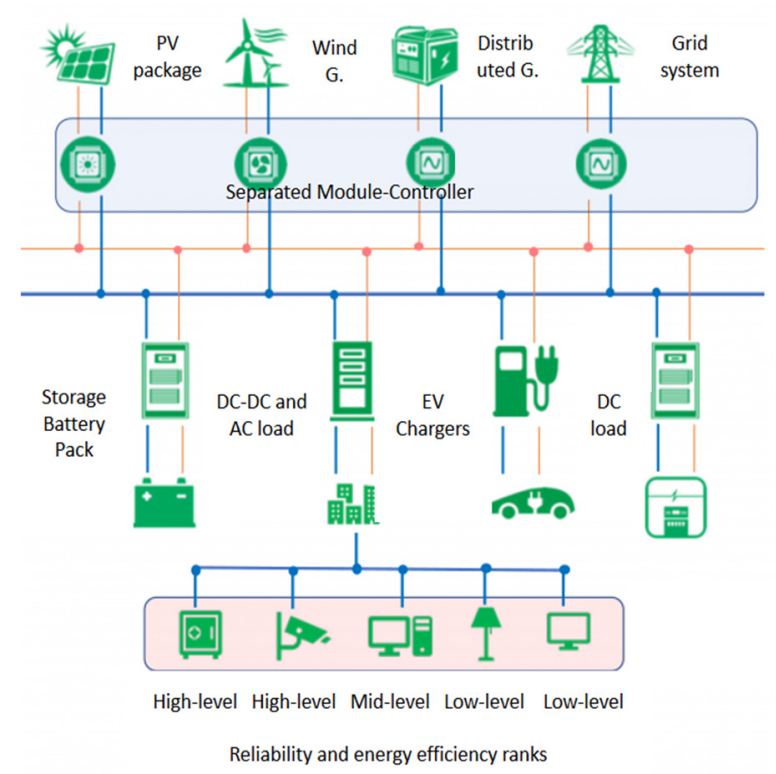

Fig. 1. Schematic form of a typical local energy internet

The development of the Energy Internet can promote a more stable, economical, cleaner and safer energy supply in China, there is still a serious waste in multi-source power coordination and optimization for the Energy Internet in China. The first problem is the lack of scientific and reasonable optimization control algorithms. It is necessary to study coordinated optimization control algorithms including diversified services, optimize the balance between supply and demand, improve the level of optimal allocation of power resources, and achieve 
effective and reasonable use of energy. Secondly, users' unreasonable energy usage habits and the low efficiency of the equipment have unintentionally increased power consumption, causing serious energy waste. It is necessary to improve energy utilization from both user energy usage habits and the energy efficiency of electrical equipment, as well as to encourage users forming good energy consumption habits. The construction of the evaluation index system and the comprehensive evaluation of the planning scheme are the key issues that must be resolved to properly evaluate the energy utilization efficiency of the local energy internet. At present, various evaluation methods based on operations research, such as analytic hierarchy process (AHP) method [2-3], data envelopment method [4-5], entropy weight analysis method [6-8], etc., have been developed as the focus point among domestic and foreign research The AHP method can quantify the subjective and empirical judgments of evaluators in multiple dimensions, and thus has been gradually introduced to the evaluation of power systems. However, there is still less of a solar power consumption-considered evaluation method for the local energy internet.

In response to the above-mentioned problems, scholars have conducted in-depth research on the multiple coordination optimization system of the Energy Internet. Literature [9] analyses and proposes a generalized 'source, network, one load, one storage' coordinated and optimized operation mode of the energy Internet, and summarizes the key technologies of energy Internet coordination and optimization. Literature [10] uses the principle of information entropy to solve the weight distribution of different indicators, and combines the weights of the importance indicators determined by expert evaluation methods to establish a multi-index system program evaluation model. Literature [11] applied AHP-entropy weight method to comprehensively weight all levels of indicators, and established a comprehensive evaluation model. Literature [12] established a smart grid innovation demonstration zone energy Internet evaluation index system from the perspectives of economy, energy, environment, society and engineering.

This article focuses on the reliability of power supply, energy utilization efficiency, solar power consumption, and investment economy to build a comprehensive evaluation index system for the local energy Internet planning program, so as to explorer a multi-dimensional comprehensive evaluation method that can be widely applied to the solar-related local energy internet. The key factors affecting energy efficiency in the local energy system was studied and a multi-source optimization energy efficiency evaluation system for the local energy Internet was established. Through the definition of the first-level energy efficiency index and the objective evaluation of the second-level index based on the entropy weight method, the establishment of the comprehensive evaluation model of the regional energy Internet multisource optimization energy efficiency is achieved. Finally, a calculation example is analysed by taking the multisource coordinated optimization operation of an anonymous science smart grid park in Shandong as an example to verify the scientific rationality of the evaluation indicators and methods, and finally give out the energy efficiency evaluation conclusion.

\section{MODELING OF THE AHP EVALUATION ON DISTRIBUTED- SOLAR-INVOLVED ENERGY INTERNET}

\subsection{Building AHP model adapted to Distributed solar-involved energy internet}

AHP is a multi-objective and multi-criteria decisionmaking method that combines qualitative and quantitative analysis. The relative importance (weight) between the factors is determined by comparing the factors in the same level. The importance of factors at the next level requires consideration of both the current level and the weighting factors of the previous level.

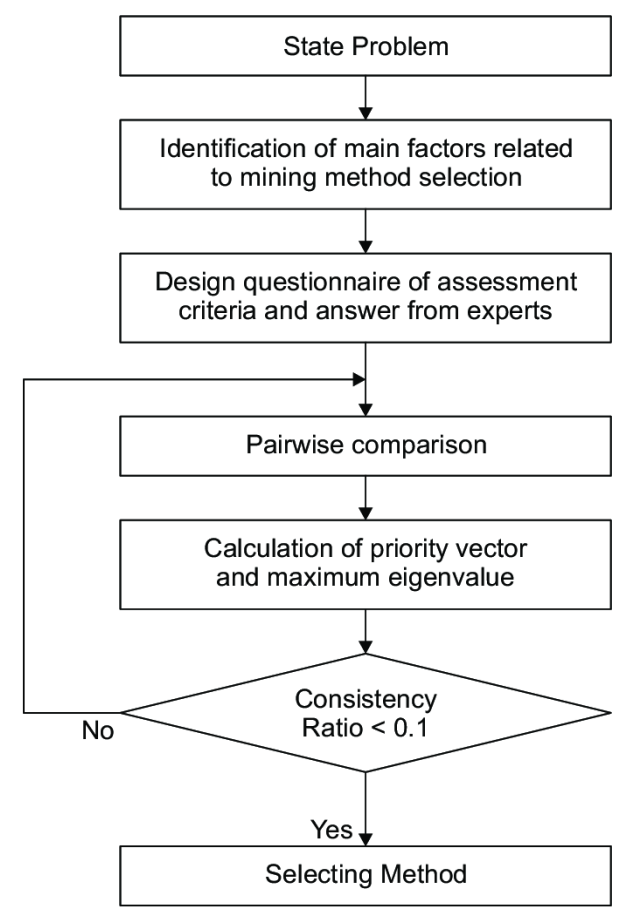

Fig. 2. Flow chart of AHP method

The basic steps of AHP are explained below. Also the flow chart of the AHP method can be referred to Fig. 2.

2.1.1 Clarify the problem and the analysis scope, understand the factors contained in the problem, and determine the relationship and affiliation between the factors.

\subsubsection{Establish an evaluation model.}

According to the analysis and understanding of the problem, the factors contained in the problem are summarized into groups according to whether there are some common characteristic. The factors themselves are also combined according to other characteristics to form 
higher-level factors, until finally a single highest-level factor is formed. The levels should not intersect each other, and the factors of the upper level dominate all or part of the factors of the adjacent next level, forming a top-down domination relationship. Finally, the evaluation model includes target layer, criterion layer, index layer, and program layer. The highest level is the target level, the middle level is the criterion level, the index level is again, and the lowest level is the program level. Each layer is composed of several factors. The hierarchical structure between each layer and the subordination relationship of each factor can be expressed by the block diagram, which is called a hierarchical structure diagram. When a certain level contains many factors, the level can be further divided into several sub-levels.

Generally, each element in each level does not exceed 9 elements (this is a boundary based on human cognitive and psychological laws, because too many dominating elements will bring difficulties to the final comparison).

\subsubsection{Construct a comparison judgment matrix (or vector)}

The judgment matrix represents the relative importance of the pairwise comparison between the indicators at the previous level. This relative importance is represented by a value to form the judgment matrix. In this paper, the judgment matrix is referred to the previous research to maintain consistency to facilitate the comparison [13]. Its reciprocal and the factors contained in each level can be compared with each other using a factor of the previous level as a comparison criterion.

In decision-making, the variable $\mathrm{Z}$ is usually expressed as a combination of variables:

$$
Z=w_{1} x_{1}+w_{2} x_{2}+\ldots+w_{n} x_{n}
$$

Where $w=\left(w_{1}, w_{2}, \ldots, w_{n}\right)^{T}$ is the weight vector. The formulation of the weight vector is a subjective component in the analytic hierarchy process.

The comprehensive evaluation value is obtained by weighting and summing the value of each index and its corresponding weight coefficient, as shown in the following formula.

$$
y=\sum_{i=1}^{n} \omega_{i} x_{i}
$$

In the formula: $\mathrm{n}$ is the total number of indicators; $\mathrm{y}$ is the comprehensive evaluation value; $\mathrm{xi}$ is the value of indicator $i$.

\subsubsection{Hierarchical list sorting and consistency check}

The process of calculating the relative value (the weight value) of the index of this level to a certain index of the previous level according to the judgment matrix is called the single-level ranking. The method adopted is to find the eigenvector corresponding to the largest eigenvalue of the judgment matrix and normalize it.

Since the evaluation object is a complex system, different experts have inevitable diversity or one- sidedness in understanding issues. Even with a nine-level scale, it may not always ensure that each judgment matrix has complete consistency. When the degree is large, it may get wrong calculation results. Therefore, it is necessary to check whether there is a contradiction between the weights of the indicators at the same level through a consistency test. The consistency test can be done by calculating the consistency ratio.

\subsection{Formulation of AHP method model}

According to the definition and implementation purpose of the Energy Internet, it is obvious that a multi-objective comprehensive evaluation index system for smart energy systems should be constructed from 3 aspects: power supply reliability, equipment utilization efficiency, solar power investment efficiency and economy.

The arrangement of the weight distribution is mainly decided by the experienced expert or a well-tested standard of the operation department. Weighing is a subjective assessment that evaluate the importance of each indicator. For example, an environmental-concerned planner will pay more weight on the solar energy consuming and investment efficiency evaluation, the AHP method thus reflect directly the planner's willingness and objectively the evaluated system's energy efficiency. In this paper, the weighing process was carried out by the researchers form State Grid Shandong Electric Power Research Institute that were authorized by the Shandong Grid Company. All weighing index are decided in reference to the relative researches as well as the inner operation standards.

System safety and reliability

The safety and reliability of the system include the average power outage time and the average number of power outages.

The average user outage time refers to the average number of outage hours of a user during the statistical period (usually 1 year). The reliability rate of power supply in the demonstration area of this case can reach $99.999 \%$ for the power supply unit (PSU), which is 0.5 $\mathrm{h} / \mathrm{PSU}$. The average number of power outages for users refers to the average number of power outages for users during the statistical period (usually 1 year).

Since the self-healing distribution network uses circuit breakers as the main section switch of the line, which greatly reduces the scope of the fault, this paper takes the average number of power outages as 0.1 times/PSU.

The calculated comprehensive reliability weights are then decided, of which the average power outage time of users as 0.12 , the average number of power outages of users as 0.08 , total of which weighing 0.2 .

The power supply reliability rate refers to the ability of the power supply system to continuously supply power. It is an important indicator for assessing the power quality of the power supply system and reflects the degree of satisfaction of the power industry to the national economic power demand. The higher it is, the higher the overall energy efficiency level of the entire distribution network, which can be expressed as: 


$$
\chi=\left(1-T_{1} / T_{2}\right) \times 100 \%
$$

Among which $\chi$ is the power supply reliability, ${ }{ }_{1}$ is the average outrage time, ${ }^{T_{2}}$ is the statistic period time.

Efficiency of energy and equipment utilization

The equipment utilization efficiency index is a quantitative index reflecting the use of regional smart energy applications to improve the utilization efficiency of power grid equipment assets. It mainly involves the load situation of distribution lines, proportion of heavy /lightload substations and the peak-to-valley ratio of the regional load.

The line average load rate is an important parameter reflecting the load level of the transmission line. The higher the line load rate, the higher the utilization rate and the more economical it is, which can be expressed as:

$$
\beta_{L}=I_{\max } / I_{s} \times 100 \%
$$

$\beta_{L}$ is the line average load rate, ${ }^{{ }_{\max }}$ is the max line load, $I_{s}$ is the line current safety limit value.

The proportion of heavy /light-load substations is an important parameter reflecting the operation efficiency of the distribution transformer. The normal load rate of the distribution transformer ranges from $30 \%$ to $70 \%$. When it is less than $30 \%$, it will cause low efficiency of the distribution voltage device. When it is greater than $70 \%$, the distribution transformer will be overloaded and overloaded. This can be expressed as:

$$
\beta_{T}=\left(\sqrt{3} U_{N} I_{\max } / S\right) \times 100 \%
$$

$\beta_{T}$ is the distribution transformer average load rate, $U_{N}$ is the rated voltage of the transformer, $I_{\max }$ is the maximum current in transformer, $\mathrm{S}$ is the rated transformer capacity.

Peak load ratio is the ratio of the peak load of the relevant users in the area to the low valley load, which can be expressed as:

$$
\beta_{P-V}=S_{v} / S_{p} \times 100 \%
$$

Among which $\beta_{P-V}$ is the Peak load ratio, $S_{v}$ is the valley load of the system during the day, $S_{p}$ is the peak load during the day.

Based on the above indicator system and judgment matrix, the AHP method is used to calculate the weight of each indicator, and the results are shown in Table I and Table II separately. In the actual calculation, the deviation of each indicator value needs to be standardized from 0 to $100 \%$.

Table 1. The Indicator Definition And Weighing Of The Energy And System Utilization Efficiency

\begin{tabular}{|c|c|c|}
\hline Indicators & Definition & Weight \\
\hline $\begin{array}{c}\text { Solar power } \\
\text { penetration } \\
\text { ratio }\end{array}$ & $\begin{array}{c}\text { Ratio of distributed solar } \\
\text { power generation to } \\
\text { regional maximum load }\end{array}$ & 0.15 \\
\hline
\end{tabular}

\begin{tabular}{|c|c|c|}
\hline $\begin{array}{c}\text { Solar power } \\
\text { consumption } \\
\text { ratio }\end{array}$ & $\begin{array}{c}\text { The ratio of distributed } \\
\text { solar power consumption } \\
\text { to actual regional power } \\
\text { consumption }\end{array}$ & 0.1 \\
\hline $\begin{array}{c}\text { Solar system } \\
\text { invest- } \\
\text { economy }\end{array}$ & $\begin{array}{c}\text { The internal rate of return } \\
\text { and investment payback } \\
\text { period for building a local } \\
\text { energy internet with } \\
\text { distributed solar power } \\
\text { system }\end{array}$ & 0.1 \\
\hline Total & - & 0.35 \\
\hline
\end{tabular}

Solar power penetration ratio represents the ratio of distributed solar power generation to regional maximum load, which can be expressed as:

$$
f_{1}=S_{p v} / L
$$

Among which $S_{p v}$ is the distributed solar power total generation, $L$ is the regional maximum load.

Solar power consumption ratio represents the ratio of distributed solar power consumption to actual regional power consumption, which can be expressed as:

$$
f_{2}=A / Q
$$

Among which $\mathrm{A}$ is the average solar power consumption of the regional grid, $\mathrm{Q}$ is the actual regional power consumption

Solar system invest-economy represents the overall description of the distribution network power supply load corresponding to the unit investment, which can be expressed as:

$$
f_{3}=P / G
$$

Among which $\mathrm{P}$ is the average system investment, $\mathrm{G}$ is the overall system load.

The weight values of each solar power evaluation indicators are displayed in Table II.

Table 2. The Indicator Definition And Weighing Of The Distributed Solar Power Exploitation Efficiency

\begin{tabular}{|c|c|c|}
\hline Indicators & Definition & Weight \\
\hline Line average & $\begin{array}{c}\text { Through the adjustment of } \\
\text { grid operation mode, } \\
\text { demand response and } \\
\text { distributed energy access } \\
\text { and other technical means, } \\
\text { the load rate of medium } \\
\text { voltage distribution lines } \\
\text { in the region is controlled } \\
\text { under a reasonable range. } \\
\text { Therefore, the average line } \\
\text { load factor index is } \\
\text { defined as the average } \\
\text { value of the annual } \\
\text { maximum load factor of } \\
\text { the medium voltage line in } \\
\text { the demonstration area. }\end{array}$ & \\
\hline
\end{tabular}




\begin{tabular}{|c|c|c|}
\hline $\begin{array}{c}\text { proportion of } \\
\text { heavy /light- } \\
\text { load } \\
\text { substations }\end{array}$ & $\begin{array}{l}\text { Substations with a load } \\
\text { rate over } 80 \% \text { classified as } \\
\text { heavy-duty substations. } \\
\text { Those with a load rate } \\
\text { under } 20 \% \text { classified as } \\
\text { light-load substations, the } \\
\text { proportion of heavy- } \\
\text { load/light-load substations } \\
\text { is the ratio of the number } \\
\text { of heavy-load substations } \\
\text { and the number of light- } \\
\text { load substations to the } \\
\text { number of substations in } \\
\text { the region. }\end{array}$ & $\begin{array}{c}\text { Heavy: } \\
0.3 \\
\text { Light: } \\
0.9\end{array}$ \\
\hline $\begin{array}{l}\text { Peak load } \\
\text { ratio }\end{array}$ & $\begin{array}{l}\text { The ratio of the peak load } \\
\text { of the relevant users in the } \\
\text { area to the low valley } \\
\text { load. The smaller the ratio, } \\
\text { the more stable the load, } \\
\text { the more fully utilized the } \\
\text { power supply equipment } \\
\text { and the effective play of } \\
\text { demand response. } \\
\text { Through the } \\
\text { implementation of demand } \\
\text { response and distributed } \\
\text { energy construction, peak } \\
\text { shaving and valley filling } \\
\text { are realized, which is } \\
\text { expected to reduce the } \\
\text { peak-to-valley load ratio } \\
\text { by } 19 \% \text {. }\end{array}$ & 0.18 \\
\hline Total & & 0.45 \\
\hline
\end{tabular}

The above indicator weights are formulated with reference to the corresponding research data, and are finally obtained by relevant experts' evaluation and adjustment. Because its weight distribution system is goaloriented, its subjective components are inevitable, so it is necessary to apply it to specific examples for verification.

\section{Experimental analysis}

Given the AHP method and the weighing process of the evaluation indicator, an improved AHP model to evaluate solar-involved energy system has been well built. In this chapter an experimental analysis was draw to verify and examine the model's effectiveness.

An anonymous Science and Technology Park in Shandong province is a newly built multifunctional park with a total land area of 260 hectares. The planning function is mainly high-end service manufacturing and logistics park, supplemented by auxiliary functions such as business facilities, and has high requirements for power supply reliability. The long-term annual capacity reaches about $320 \mathrm{MW}$, the installed load capacity is about 270 $\mathrm{MW}$, the average load density is $103.85 \mathrm{MW} / \mathrm{km} 2$, the load is concentrated and the density is high. At the same time it has a larger peak-to-valley load ratio.

With roofs, parking lots and green ground as the main places, 15.6 MW of distributed solar power are installed. The current total industrial motor load is about $168 \mathrm{MW}$. The solar power penetration ratio is $9.7 \%$, which is low and limited by the unbuilt energy storage that is under planning.

Based on the above indicator system and judgment matrix, the AHP method is applied and the scores of the energy system are displayed in Table 3 in details.

Table 3. The Indicators' Evaluated Value And Final Scores Of An Example Energy Internet

\begin{tabular}{|c|c|c|c|c|}
\hline $\begin{array}{c}\text { Main } \\
\text { section }\end{array}$ & Indicators & $\begin{array}{c}\text { Evaluate } \\
\text { d Value }\end{array}$ & $\begin{array}{c}\text { Indicators } \\
\text {, scores }\end{array}$ & $\begin{array}{l}\text { Main } \\
\text { scores }\end{array}$ \\
\hline \multirow[t]{2}{*}{ Reliability } & $\begin{array}{l}\text { average } \\
\text { power } \\
\text { outages } \\
\text { number }\end{array}$ & 0.2 & 0.076 & \multirow[t]{2}{*}{$0.19 / 0.2$} \\
\hline & $\begin{array}{l}\text { power } \\
\text { supply } \\
\text { reliability }\end{array}$ & 0.99999 & 0.114 & \\
\hline \multirow{3}{*}{$\begin{array}{l}\text { Energy } \\
\text { utilization } \\
\text { efficiency }\end{array}$} & $\begin{array}{c}\text { Line } \\
\text { average } \\
\text { load rate }\end{array}$ & $55 \%$ & 0.161 & \multirow{3}{*}{$\begin{array}{c}0.428 / 0.4 \\
5\end{array}$} \\
\hline & $\begin{array}{l}\text { proportion } \\
\text { of heavy } \\
\text { /light-load } \\
\text { substations }\end{array}$ & 0 & 0.12 & \\
\hline & $\begin{array}{l}\text { Peak load } \\
\text { ratio }\end{array}$ & 2.2 & 0.147 & \\
\hline \multirow{3}{*}{$\begin{array}{c}\text { Solar } \\
\text { power } \\
\text { exploitatio } \\
n \\
\text { efficiency }\end{array}$} & $\begin{array}{c}\text { Solar power } \\
\text { penetration } \\
\text { ratio }\end{array}$ & $9.7 \%$ & 0.086 & \multirow{3}{*}{$\begin{array}{c}0.266 / 0.3 \\
5\end{array}$} \\
\hline & $\begin{array}{l}\text { Solar power } \\
\text { consumptio } \\
\text { n ratio }\end{array}$ & $95 \%$ & 0.09 & \\
\hline & $\begin{array}{c}\text { Solar } \\
\text { system } \\
\text { invest- } \\
\text { economy }\end{array}$ & 6 & 0.09 & \\
\hline Total & - & - & - & $0.884 / 1$ \\
\hline
\end{tabular}

It can be included from Table 3 that the reliability index of the power distribution system built in the park is relatively high and it is more friendly to industrial power users. Affected by the relatively large peak and valley load, the overall system energy efficiency score is low. Due to policy influences, more and more new parks are paying more attention to the efficiency of new energy development. Due to the fact that the energy storage module in the park has not yet been completed, the solar power installed capacity is limited. Therefore, the solar power penetration ratio is only $9.7 \%$, which is seriously lower than the average industry level. As a result, the solar power exploitation efficiency score is low, and the overall AHP evaluation of the energy internet is low.

The suggestion for improving the energy efficiency of the park is to add corresponding energy storage modules. This method can not only greatly reduce the peak-tovalley load ratio, but also further increase the installed capacity of solar power, leading to an increase in multiple ratings. At the same time, compared with other evaluation methods, the AHP method in this article focuses on expanding the scoring items of a single new energy-solar power, such as energy storage and other forms of new energy evaluation. 


\section{Conclusions}

Aiming at the implementation purpose of the energy Internet in the park, this article focuses on the solar power exploitation in terms of power supply reliability, energy utilization efficiency, clean energy consumption and investment economy, and establishes a complete energy internet evaluation index system to achieve a good combination between the objectivity of data information and the subjectivity of expert preference. The energy internet construction project of a certain industry park was taken as an example for analysis. The comprehensive evaluation index system of the park's Energy Internet planning scheme has been constructed from the three aspects of system power supply reliability, energy and equipment utilization efficiency, and photovoltaic investment utilization. The improved AHP method can objectively reflect the planning's efficiency from multi indicators.

The indicator weighing system of the AHP method is highly objective-oriented. When evaluating a local energy internet efficiency, from a different perspective, paying attention to the different characteristics of the regional power grid will lead to changes in the AHP evaluation weighting and the results. It was found that the improved AHP method is more delicate when evaluate the solarinvolved energy system. This article focuses on the development and utilization characteristics of solar power, of which the weight is as high as $35 \%$. It is suggested to list the new energy indicators separately based on policy objectives and the principle of evaluation dominance, which can decrease the ambiguity and improve the evaluation accuracy of the AHP method in the evaluation of energy internet efficiency.

\section{Acknowledgment}

This work was supported by the Science and Technology Project of State Grid Shandong Electric Power Company under Grant No. 520626200020.

\section{References}

1. T. Zang, Y. Xiang, J. Yang, X. Wei, H. Sun and Z. He, "Research Framework of the Human-Cyber-Energy Coupled Urban Energy Internet Catastrophe Analysis and Its Dynamic Early Warning," 2019 IEEE 3rd Conference on Energy Internet and Energy System Integration (EI2), Changsha, China, 2019, pp. 17761781.

2. K. $\mathrm{Wu}, \mathrm{Z} . \mathrm{Xu}$ and $\mathrm{C}$. Duan, "Research and Implementation of Evaluation System Model for Grid Investment Based on Improved Fuzzy-AHP Method," 2011 10th International Symposium on Distributed Computing and Applications to Business, Engineering and Science, 1, pp. 350-353 Wuxi, 2011.

3. Y LIU, C YUEN, N MEMBER S et al., "Electricity Cost Minimization for a microgrid with distributed energy resource under different information
availability[J]", IEEE Transactions on Industrial Electronics, vol. 62, no. 4, pp. 2571-2583, 2015.

4. Xinglin YANG, Xingxing LUO, Yubao WANG et al., "Distributed energy system efficiency optimization modeling research[J]", Journal of Jiangsu University of Science and Technology, vol. 29, no. 2, pp. 138142,2015 ..

5. G Li, Z Zhang, X Li et al., "A methodology for power quality evaluation in distribution network with distributed generation[C]/ / Critical Infrastructure (CRIS)", 2010 5th International Conference on. IEEE, pp. 1-6, 2010.

6. M. Young, The Technical Writer's Handbook. Mill Valley, CA: University Science, 1989.

7. L Li, L Liu, C Yang et al., "The Comprehensive Evaluation of Smart Distribution Grid Based on Cloud Model[J]", Energy Procedia, pp. 96-102, 2012.

8. .G C Liao and J I. Tsai, "Use a New Method to Solve the Economic Dispatch Problem of Smart MicroGrid Including Distributed Generation [J]. IEEE", vol. 27, no. 5, pp. 1-4, 2012.

9. .M Enkhtuvshin, K Z Liu and T. Zanma, "Economic operation of smart grid based on the statistics of renewable energy[C]/Smart Grid Technologies Asia. IEEE", 2015.

10. ZHAO Y F, CHEN J F. Analytic hierarchy process and its applicationin power system [J]. Electric Power Automation Equipment,2004, 24(9): 85-89.

11. CAI Jingtao, LI Zhikeng, ZHAO Qingyu, "Research on Benefit Evaluation Method of User Side Distributed Energy Storage System",Southern Energy Construction,Vol. 6 No.3, pp.75-80,2019.

12. LIU S, DU S X. "Fuzzy comprehensive evaluation based on data envelopment analysis". Fuzzy Systems and Mathematics, 24(2): pp.93-96,2010. 